\title{
Plews, John L. and Spokiene, Diana (eds.). Translation and Translating in German Studies: A Festschrift for Raleigh Whitinger. Waterloo: Wilfred Laurier University Press, 2016.
}

\author{
Spencer Nelson \\ University of Alberta, Canada
}

Raleigh Whitinger, now professor emeritus at the University of Alberta, was - and is - passionate about translating. For those of us who know him or who have had the pleasure to attend his courses, it is difficult to avoid catching some of his infectious enthusiasm for this craft. Translation and Translating in German Studies, a festschrift dedicated to this "well-loved scholar" (Plews \& Spokiene, 2016, p. ix), brings together a diverse array of essays "examining translation as a key site for bridging language, literature/culture, and pedagogy/experiential education" (p. 2). It is a fitting tribute to the man and his equally diverse career.

The volume contains 19 essays from 24 contributors. They are, for the most part, professors of German studies, literature, or translation studies at Canadian universities, with six additional contributors representing international institutions. It assumes a bilingual readership, leaving quotations in the original German. The introduction, written by Diana Spokiene - one of the book's editors and a perennial co-author with Whitinger - summarizes the major points in the history of translation studies and defines the terms used in the title: translation, the product, and translating, the process. The introduction also outlines the thematic organization of the book, which consists of sections of two to four chapters, each dealing with a specific theme. These themes include translation practices for engaging with early feminist German authors, inter- and transmediality, and their potential for pushing literary or genre boundaries, and translation as a pedagogical practice in the post-secondary language classroom.

The diversity of and within these categories is one of the greatest strengths of the book. Interspersed among fruitful commentary on translation theory and translation in practice, highlights include Chapter 3, with the entertaining title "Vegetable Genius and the Loves of the Plants: Botany in German Poetry around 1800". The content of this essay is no less entertaining than its title, presenting fascinating research into the lurid plant-sex metaphors of the "distinctly German tradition of translating Linnean botany into poetic form" (p. 46). The chapter describes how this code was used to subvert taboos, including the discussion of gendered social roles. 
The seventh chapter contains a timely application of the ever-broadening idea of translation to the "process of transition and self-translation" experienced by exiles (p. 113) - voluntary or otherwise. It analyzes early women's emancipation advocate Johanna Kinkel's Hans Ibeles in London: Ein Familienbild aus dem Flüchtlingsleben, which was published in 1860 as a fictional, posthumous, and semiautobiographical account of its author's experiences as a political refugee living in England. The essay quite productively addresses the events portrayed in the novel - border crossings, culture shock and psychological trauma, difficulties in establishing a life in the new land - in terms of foreignization, domestication and other concepts taken from the sphere of translation studies. I find this study especially relevant given the current refugee situation unfolding in the Middle East and Europe.

The similarly punctual fourteenth chapter argues for the emergence of a new "literature of movement" (p. 227), distinct from transcultural literature. "The crucial factor for figures within these texts," says essay author Katelyn Petersen, "is not where they are located, or where they are moving toward, but rather the act and process of movement itself' (p. 230). Such texts place increased demands on the reader due to their de-emphasis or utter lack of recognizable settings or "signposts". This essay also contains an interesting discussion of the idea of translation as betrayal, an act that will inevitably be unfaithful to the original.

The final chapter, "What New Music? On Versions of the Translating Self of Study Abroad", reminded me fondly of my own early experiences in a study abroad program. It undertakes to "use the idea of translation to explore the identity work of second-language study abroad participants” (p. 301). It does this by means of an analysis of interviews with three young Canadian women, who studied for a short time in Germany. One of the most insightful components of this essay is found in a comment offered by one of these young women, who describes how there are "many expressions that don't exist in German that exist in English [...]. You don't speak the same language and ... your personality isn't different, it just comes out differently" (p. 301). Each of the women reported experiencing changes in their identity and self-perception as a result of their attempts to present themselves using an alternative set of codes within a different semiotic framework - a process of transferral that bears clear resemblance to that undergone by texts in translation.

The main strength of the book, that of approaching the question of translation from many different angles, also leads at times to its primary weakness. The connection of some texts to the book's stated theme can occasionally be quite tenuous; the concept of "translation" thereby distorted to the point of near meaninglessness, as is the case with the thirteenth chapter. Spokiene's introduction presents this chapter as exploring "the role of cultural translation in the search for identity across different cultures and between generations and genders" (p. 10). I found this to be somewhat of a 
stretch, as the chapter in question, though interesting and well-reasoned in its own right, comes across as pure literary criticism with only the most passing and indirect nod to translation in any recognizable form. There were also sporadic instances of segments that could have benefitted from an additional editing pass, such as the sixth chapter, in which the first six pages tend toward repetitiveness. This essay does finally find its pace when it dives into a detailed comparative analysis of several editions and translations of Hedwig Dohm's 1876 Der Frauen Natur und Recht.

These minor quirks do not distract from the overall impression of the volume as a thoughtfully laid-out and largely well-written compilation. The individual articles comprising the book are generally suggestive of careful research and contribute meaningfully to their fields and to an interdisciplinarity within translation studies. As both a tribute to a respected scholar and as a body of scholarship per se, Translation and Translating is easy to recommend to any reader interested in either German or translation studies. 